\title{
Rapid Synaptic Transmission in the Avian Ciliary Ganglion Is Mediated by Two Distinct Classes of Nicotinic Receptors
}

\author{
Erik M. Ullian, ${ }^{1}$ J. Michael Mclntosh, ${ }^{2}$ and Peter B. Sargent ${ }^{1}$ \\ ${ }^{1}$ Neuroscience Graduate Program and Departments of Stomatology and Physiology, University of California, San \\ Francisco, California 94143, and 2Departments of Psychiatry and Biology, University of Utah, Salt Lake City, Utah 84112
}

\begin{abstract}
We analyzed the kinetics and pharmacology of EPSCs in two kinds of neurons in the embryonic avian ciliary ganglion. Wholecell voltage-clamp recordings revealed that the singly innervated ciliary neurons had large-amplitude (1.5-8.0 nA) EPSCs that could be classified according to the kinetics of their falling phases. Most of the neurons responded with an EPSC the falling phase of which followed a double exponential time course with time constants of $\sim 1$ and $10 \mathrm{msec}$. The EPSCs of the remaining ciliary neurons followed a single time constant ( $\sim 8 \mathrm{msec}$ ). Multiple innervated choroid neurons had smalleramplitude responses $(0.2-1.5 \mathrm{nA}$ when all inputs were activated) that appeared to contain only a slowly decaying component ( $\tau=12 \mathrm{msec}$ ). The fast and slow components of EPSC decay seen in most ciliary neurons could be pharmacologically
\end{abstract}

isolated with two toxins against nicotinic acetylcholine receptors (AChRs). The fast component was blocked by $50 \mathrm{~nm}$ $\alpha$-bungarotoxin ( $\alpha$-BuTx), which binds $\alpha 7$-subunit-containing AChRs. The slow component was selectively blocked by $50 \mathrm{~nm}$ $\alpha$-conotoxin MII ( $\alpha$-CTx-MII), which blocks mammalian AChRs containing an $\alpha 3 / \beta 2$ subunit interface. A combination of both $\alpha$-BuTx and $\alpha$-CTx-MII abolished nearly all evoked current. Similar pharmacological results were found for ciliary neurons with monoexponentially decaying EPSCs and for choroid neurons. These results suggest that nerve-evoked transmitter acts on at least two different populations of AChRs on autonomic motor neurons in the ciliary ganglion.

Key words: acetylcholine receptors; excitatory postsynaptic current; $\alpha$-bungarotoxin; $\alpha$-conotoxin MII; $\alpha 7$; $\alpha 3$; $\beta 2$
Nicotinic acetylcholine receptors (AChRs) are a family of ligandgated oligomeric ion channels assembled from a pool of 15 or more unique subunits. The application of recombinant DNA technology has revealed a rich spectrum of AChR subunit genes expressed by neurons (for review, see Sargent, 1993; Decker et al., 1995; McGehee and Role, 1995; Lindstrom, 1996; Role and Berg, 1996; Albuquerque et al., 1997). Rapid excitatory synaptic transmission in autonomic neurons is mediated by AChRs, and autonomic neurons must therefore make at least one class of receptors that underlie that function. Many autonomic neurons, however, express mRNAs and gene products corresponding to several AChR subunits and may be capable of assembling them into several different oligomeric AChRs (Listerud et al., 1991; Corriveau and Berg, 1993; Mandelzys et al., 1995). This raises the question of whether these AChRs serve novel roles in addition to their classic role.

We have studied AChR function in parasympathetic motor neurons of the embryonic chicken ciliary ganglion, in which $\mathrm{AChR}$ expression is diverse and AChRs may serve novel roles. At least five different $\mathrm{AChR}$ subunit genes- $\alpha 3, \alpha 5, \alpha 7, \beta 2$, and $\beta 4$-are expressed in the ciliary ganglion, and it is likely that each neuron expresses the full complement of subunits that is found in the ganglion as a whole (Boyd et al., 1988; Corriveau and Berg, 1993). Several studies have established that neurons in this gan-

Received May 6, 1997; revised July 8, 1997; accepted July 10, 1997.

This work was supported by National Institutes of Health Grants NS 24207, GM 07449, MH 53631, and GM48677. We thank Drs. J. Margiotta, B. Walmsley, and D Yoshikami for critically reading a draft of this manuscript; Drs. P. Castillo, S. E. Dryer, P. Hickmott, P. H. Steen, M. Weisskopf, and H. Yawo for advice; and Ms. Evangeline Leash for editorial assistance.

Correspondence should be addressed to Dr. Peter B. Sargent, Division of Oral Biology, HSW-604, University of California, San Francisco, CA 94143-0512.

Copyright (C) 1997 Society for Neuroscience $0270-6474 / 97 / 177210-10 \$ 05.00 / 0$ glion express two major classes of AChRs, one recognized by monoclonal antibody (mAb) 35, known as mAb 35-AChRs, and another recognized by $\alpha$-bungarotoxin ( $\alpha$-BuTx), known as $\alpha$-BuTx-AChRs (Vernallis et al., 1993; Conroy and Berg, 1995; Pugh et al., 1995). Within and between these classes there is additional complexity: most of the mAb 35-AChRs include the $\alpha 3, \alpha 5$, and $\beta 4$ subunits, but a subset of these receptors has, in addition, the $\beta 2$ subunit (Conroy and Berg, 1995). There is also a relatively small number of receptors that are recognized by both mAb 35 and $\alpha$-BuTx and apparently are composed of novel AChR subunits (Pugh et al., 1995).

Chemical synaptic transmission in the ciliary ganglion is nicotinic (Martin and Pilar, 1963; Dryer, 1994) and has been attributed to mAb 35-AChRs rather than $\alpha$-BuTx-AChRs (Smith et al., 1983; Halvorsen et al., 1991). $\alpha$-BuTx does not abolish compound action potentials recorded from the postganglionic nerve in response to preganglionic nerve stimulation (Chiappinelli and Dryer, 1984). Moreover, $\alpha$-BuTx-AChRs are not concentrated in the synaptic membrane but rather are extrasynaptic (Jacob and Berg, 1983; Loring et al., 1985) or, more precisely, perisynaptic (Wilson Horch and Sargent, 1995). mAb 35-AChRs, on the other hand, are concentrated at synaptic membranes (Jacob et al., 1984; Loring and Zigmond, 1987; Wilson Horch and Sargent, 1995).

We examined whole-cell currents recorded from ciliary ganglion neurons of embryonic day 13-16 chicks and found both kinetic and pharmacological evidence that synaptic transmission is mediated in part by $\alpha$-BuTx-AChRs. Similar results have been reported recently by $Z$ hang et al. (1996). We have extended these findings by (1) analyzing synaptic currents separately in both ciliary and choroid neurons, which differ in the sensitivity of their EPSCs to $\alpha$-BuTx, and (2) dissecting the currents into those sensitive to $\alpha$-BuTx and those sensitive to the cone snail peptide 

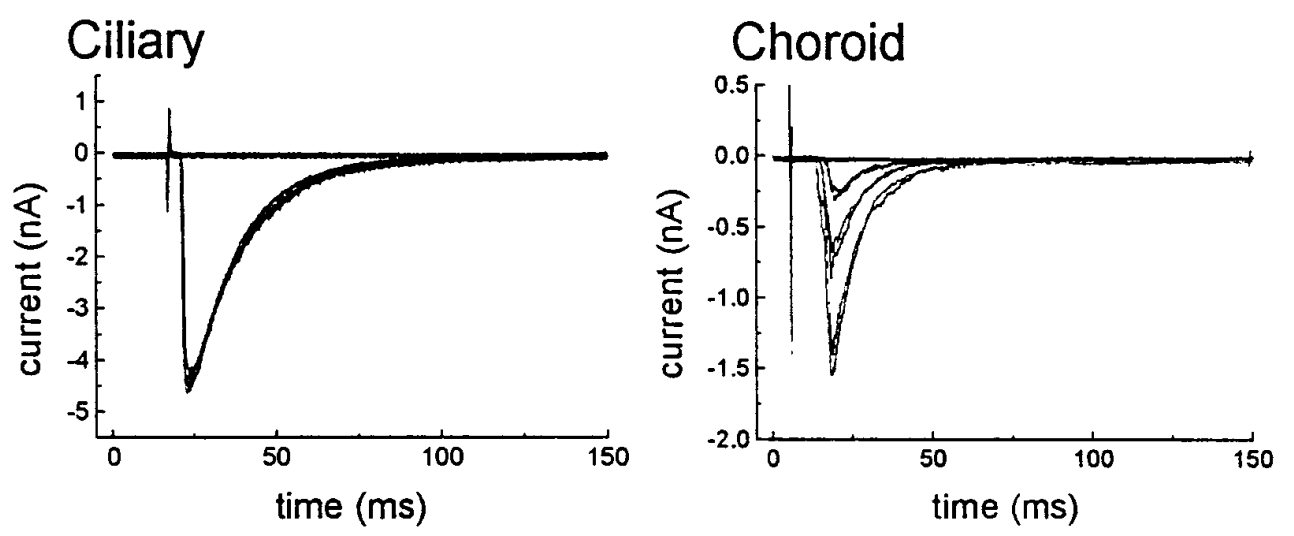

Figure 1. Ciliary and choroid neurons can be distinguished by the extent of synaptic convergence. The two panels show multiple, superimposed records of evoked synaptic currents recorded from a ciliary and a choroid neuron. Inward current is represented by a downward deflection. Preganglionic axons within the oculomotor nerve were gradually recruited by increasing the stimulus intensity delivered to the nerve via a suction electrode. In the left panel, a stimulus intensity of 1-3 V caused no synaptic current, whereas a stimulus of $>3 \mathrm{~V}$ caused a large synaptic current that fluctuated little from trial to trial. When the same paradigm was applied to a choroid neuron, the EPSC increased in several increments, each with a well-defined threshold. The choroid neuron record shows two responses at each of four stimuli, one of which elicited no response. This neuron had a minimum of three independently elicitable inputs.

$\alpha$-conotoxin MII ( $\alpha$-CTx-MII). $\alpha$-CTx-MII is specific for expressed mammalian AChRs containing an $\alpha 3 / \beta 2$ subunit interface; in the ciliary ganglion $\alpha$-CTx-MII may block currents that arise from mAb 35-AChRs.

\section{MATERIALS AND METHODS}

Chick embryos (Gallus domesticus) were obtained from Feather Hill Farms (Petaluma, CA). Embryonic day 13-16 chicks were decapitated, and ciliary ganglia were removed and pinned in a recording dish with constant flow of oxygenated glucose Ringer's solution. The sheath covering the ganglion was softened with collagenase $(4 \mathrm{mg} / \mathrm{ml}$, type A; Boehringer Mannheim, Indianapolis, IN) applied with pressure through a $15-30 \mu \mathrm{m}$ inner diameter pipette and was removed either with fine forceps or with gentle suction through the pipette (Yawo and Momiyama, 1992). To ensure that the enzyme treatment did not damage the presynaptic innervation, some ganglia were perfused with oxygenated glucose Ringer's solution for $1 \mathrm{hr}$ with no enzyme treatment and then desheathed with fine forceps. There were no statistically significant differences in EPSC amplitude or kinetics for ciliary neurons examined from enzymetreated and untreated ganglia. Neurons were viewed with a Zeiss $40 \times$ water immersion objective (numerical aperture 0.75 ). The ganglion was perfused with glucose Ringer's solution containing (in $\mathrm{mM}$ ): $\mathrm{NaCl} 150$, $\mathrm{KCl} 3, \mathrm{CaCl}_{2} 2.5$ (or 5), $\mathrm{MgCl}_{2} 4.5$ (or 2), glucose 17, and HEPES 10, $\mathrm{pH}$ 7.4. There was no statistically significant difference in EPSC amplitude or kinetics in 2.5 and $5.0 \mathrm{mM} \mathrm{CaCl}$. The pipette solution contained (in $\mathrm{mM}$ ): $\mathrm{CsCl} 140, \mathrm{Mg}$-ATP 2, GTP 0.2, EGTA 2, glucose 5, and HEPES 10 , $\mathrm{pH}$ 7.2. $\alpha$-BuTx $(50-60 \mathrm{~nm})$ was obtained from Biotoxins (St. Cloud, FL). $\alpha$-CTx-MII was synthesized as described previously (Cartier et al., 1996) and stored either lyophilized or in solution at $4^{\circ} \mathrm{C}$.

Whole-cell recording pipettes were pulled from borosilicate glass (WPI, Sarasota, FL) and had resistances of 1-5 M 2 . Electrodes were coated with Sigmacote (Sigma, St. Louis, MO). The oculomotor nerve was stimulated with a suction pipette $(0.5-1.0 \mathrm{msec}, 5-10 \mathrm{~V})$ at $30-60 \mathrm{sec}$ intervals. Synaptic currents were recorded from cells clamped at $-60 \mathrm{mV}$ with an Axopatch-1D amplifier (Axon Instruments, Foster City, CA), filtered at $2 \mathrm{kHz}(-3 \mathrm{~dB}, 8$-pole Bessel filter), digitized at $25 \mathrm{kHz}$ (TL-1 DMA interface, Axon Instruments), and collected on computer hard drive with Clampex (pClamp 6.0, Axon Instruments) while input resistance was continuously monitored. The measured series resistance (access resistance) was 3-5 $\mathrm{M} \Omega$ for ciliary neurons and 3-7 $\mathrm{M} \Omega$ for choroid neurons. Holding currents necessary to maintain a potential of $-60 \mathrm{mV}$ were from $-0.01 \mathrm{nA}$ to $-0.09 \mathrm{nA}$. A series compensation of $80 \%$ was typically used. The measured membrane capacitance was $26 \pm 4 \mathrm{pF}$ for ciliary neurons and $19 \pm 4 \mathrm{pF}$ for choroid neurons, yielding a calculated time constant with compensation for the clamp circuit of $\sim 25 \mu \mathrm{sec}$. Current records that showed an inflection during the rising phase of the EPSC were not analyzed further because of the possibility that they were accompanied by voltage escape.
Experiments were performed at $20-25^{\circ} \mathrm{C}$. Toxins were added to the bath through perfusion or by pipette. Responses were analyzed with Clampfit and pSTAT (pClamp 6.0, Axon Instruments) and Origin 4.0 (Microcal, Northhampton, MA) using log maximum-likelihood estimates. Inward currents are shown as downward deflections but are given positive values in the text. Curves were fitted from $90 \%$ of peak to $10 \%$ of baseline. Samples were compared using the Mann-Whitney test or, if samples satisfied the normality and equal variance tests, the Student's $t$ test. All values are given as the mean \pm SD.

\section{RESULTS}

\section{Neuronal types in the ciliary ganglion}

We distinguished ciliary neurons from choroid neurons by three criteria: cell location, cell body diameter, and number of preganglionic inputs (Dryer and Chiappinelli, 1987). Choroid neurons are smaller than ciliary neurons and are located within one quadrant of the ganglion (Pilar et al., 1980; Dryer and Chiappinelli, 1987). We recorded from choroid neurons by pinning the ganglion so that this quadrant was accessible and by choosing among the smallest neurons (cell body diameter $<20 \mu \mathrm{m}$ ) for recording. We recorded from ciliary neurons by pinning the ganglion so that the quadrant containing choroid neurons faced the bottom of the recording chamber and by recording from larger-diameter neurons (cell body diameter $>20 \mu \mathrm{m}$ ). We confirmed the validity of this selection procedure by noting the number of independently elicitable synaptic inputs per neuron. Choroid neurons had a minimum of three synaptic inputs, as judged by the number of abrupt increments in EPSC size evoked when the stimulus intensity was progressively increased $(n=15)$; in contrast, ciliary neurons each had a single synaptic input $(n=$ 44) (Fig. 1). Another difference between choroid and ciliary neurons is the size of the EPSC produced by maximal preganglionic stimulation. Ciliary neurons, which in the embryo have a single large, calyceal synapse, had large peak EPSC amplitudes, with a mean amplitude of $4.23 \pm 1.81 \mathrm{nA}$ (range, $1.50-8.01 \mathrm{nA}$ ). Choroid neurons, which have more conventional synapses and smaller EPSCs than ciliary neurons (Dryer and Chiappinelli, 1987), had a mean peak EPSC amplitude of $0.75 \pm 0.34 \mathrm{nA}$ in response to maximal stimulation of the preganglionic nerve (range, 0.20-1.47 nA). Thus, the number of inputs and the peak EPSC amplitude identify ciliary and choroid neurons as unique 
A

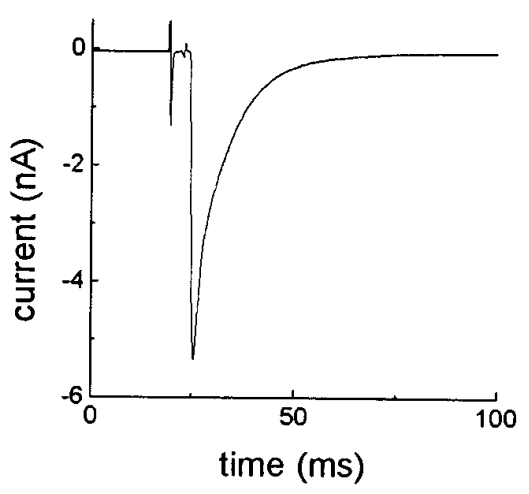

C

Figure 2. Ciliary neuron EPSC decay is either biexponential or monoexponential. $A$, A biexponential ciliary EPSC. The EPSC falling phase was best fit with two exponentials as assessed by the maximum-likelihood estimation method (pClamp 6.0). B, The EPSC replotted in semilogarithmic coordinates. The two exponential components can be seen qualitatively as linear phases of the current decay. $C$, A monoexponential ciliary EPSC. The falling phase of the EPSC was best fit with a single exponential. $D$, The EPSC replotted in semilogarithmic coordinates. The single exponential component can be seen qualitatively as a linear phase.

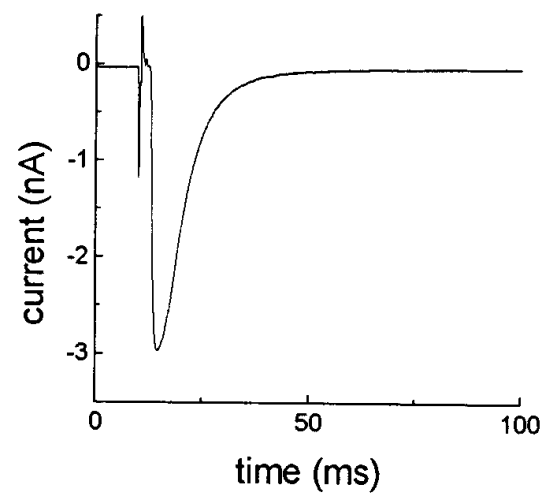

B

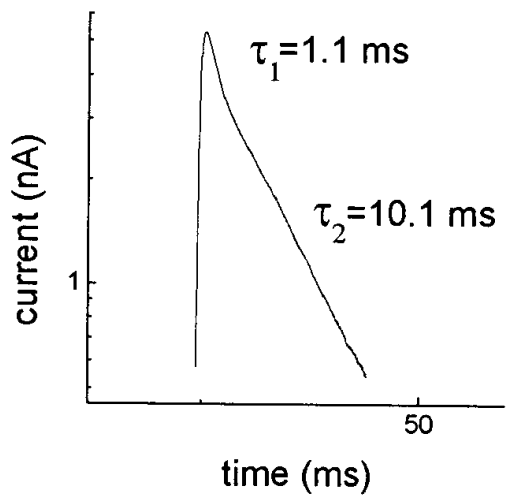

D

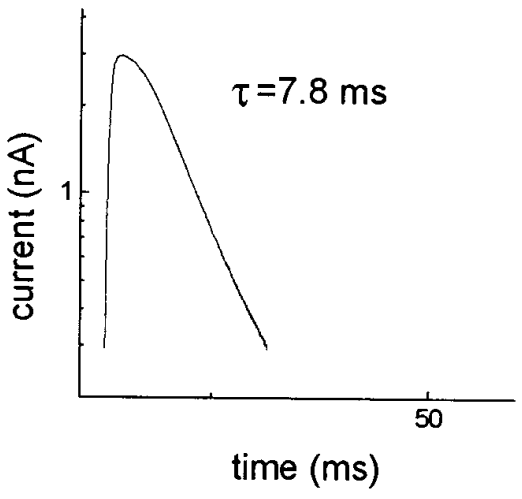

cell populations within the ganglion and support the validity of our identification criteria.

\section{Kinetic analysis of EPSCs from ciliary neurons}

Most of the ciliary neurons we encountered (28 of 44) had EPSCs the falling phases of which were not well fit with a single exponential function. An example of an EPSC from such a neuron is illustrated in Figure $2 A$. A semilog plot of this EPSC (Fig. 2B) shows that the current decays exponentially with two distinct rates. In this instance, the digitized EPSC extending from $90 \%$ of peak to $10 \%$ of baseline was significantly better fit by the sum of two exponentials than by a single exponential or by three or more exponentials. The average time constants for the rapidly and slowly decaying components of the EPSC were $1.04 \pm 0.35$ and $11.3 \pm 3.3 \mathrm{msec}$, respectively. The average fraction of the EPSC amplitude, at $90 \%$ of peak, that was accounted for by the rapidly decaying phase was $41 \%$ (range, $20-71 \%$ ). The contribution of the rapidly decaying phase is somewhat greater when the fitted curves are extrapolated back to the time when the EPSC is at its peak, and it is assumed, for the sake of the calculation, that all channels open at that time. One explanation for the biexponential decay of the EPSC in these ciliary neurons is that the synaptic current is generated by the activity of two populations of channels with different burst duration. Additional evidence for this interpretation will be provided below, where we describe pharmacological isolation of each phase of the EPSC.

Not all ciliary neurons had EPSCs that decayed biexponentially. Figure $2 C, D$ shows an example of a record the falling phase of which is best fit by a single exponential with a time constant of $7.81 \mathrm{msec}$. The average time constant of decay of the monoexpo- nential EPSCs was $8.25 \pm 2.03 \mathrm{msec}$, a number similar to the slow component of the biexponentially decaying EPSC $(11.3 \mathrm{msec})$. Ciliary neurons with a single component of EPSC decay are not likely to be damaged as compared with neurons with a twocomponent EPSC; we found no difference between these two populations of recordings with regard to seal resistance, input resistance, or the amount of current needed to hold the membrane potential at $-60 \mathrm{mV}$ (data not shown). Are these neurons qualitatively different from those with biexponentially decaying EPSCs, or do they simply represent a subset of cells with a rapidly decaying EPSC component that is too small to detect? To assess how much rapidly decaying current must be present for detection, we generated a family of biexponential curves with time constants of 1.1 and $11.0 \mathrm{msec}$ and with a variable amount of fast component (measured at $90 \%$ of the peak), and then we determined how much of the fast component must be present before it is detected by the pSTAT program. The program detected a rapidly decaying component only if $>13 \%$ of the peak current was "fast." Interestingly, this is also approximately the amount of fast component needed for the eye to readily detect a biexponential trace. Thus, it is possible that a small rapidly decaying component of synaptic current may be present in ciliary neurons that appear to have monoexponentially decaying EPSCs.

To learn whether monoexponential and biexponential EPSCs represent two extremes of a continuous population, we subjected all EPSC decays to the curve-fitting procedure assuming two components, and we then plotted the fraction of the total current attributable to the rapidly decaying component as a cumulative frequency distribution. For 13 of the 16 apparently monoexpo- 


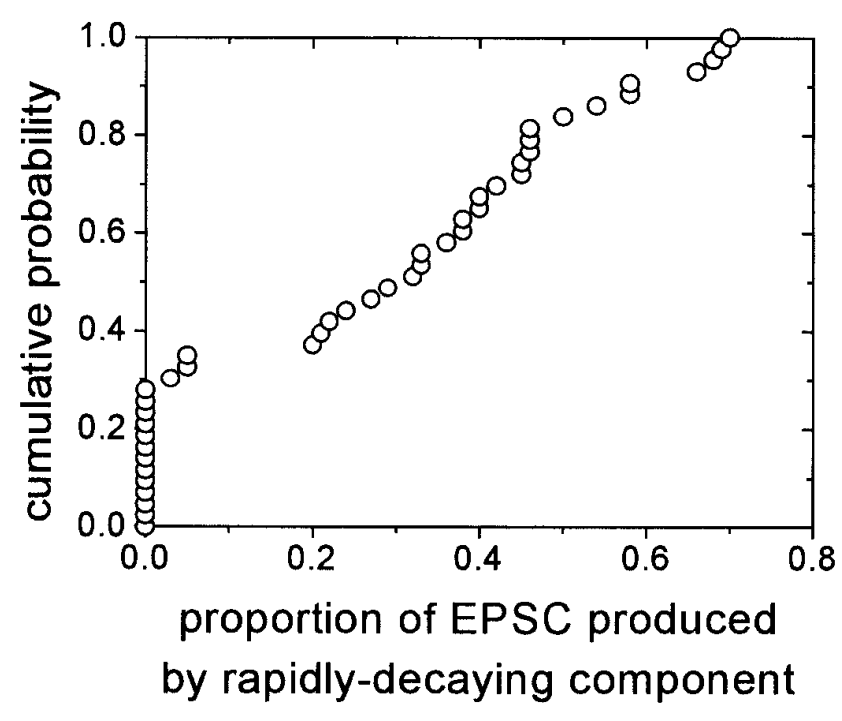

Figure 3. The cumulative distribution of the relative amount of rapidly decaying current in ciliary EPSCs suggests two distinct ciliary neuron populations. All ciliary neuron EPSCs were fitted assuming two phases of decay, and the ratio of the amplitude of the fast component to the total current (at $90 \%$ of peak) is displayed in a cumulative distribution plot. The plot shows a break in the distribution of amplitude ratios, with one group showing $20 \%$ or more of the fast component and another group showing $5 \%$ or less of the fast component.

nentially decaying EPSCs, the pCLAMP curve-fitting program produced a trivial second component of EPSC decay (e.g., with an amplitude of $10^{-5} \mathrm{nA}$ ), and we assumed that there was no rapidly decaying component in these recordings. For the three remaining apparently monoexponential recordings, the pCLAMP program assigned a small component of rapidly decaying current, amounting to $3-5 \%$ of the total. A cumulative frequency distribution for the fraction of EPSC that is fast for all 44 ciliary neurons (Fig. 3) shows a discontinuity: $36 \%$ of the neurons (16/44) have EPSCs with $<5 \%$ of the current decaying rapidly, whereas $64 \%$ of the neurons (28/44) have EPSCs with $>20 \%$ of the current decaying rapidly, but no neurons have EPSCs with intermediate values (5-20\%). This suggests that the two populations of neurons characterized as biexponential or monoexponential are distinct. Another finding that supports this interpretation is that the time constants for EPSC decay for the slow component of "biexponential" neurons and for the only component of "monoexponential" neurons are significantly different (Fig. 4) (means of $11.3 \pm 3.3$ and $8.25 \pm 2.03 \mathrm{msec}$, respectively; $p=0.016$ by Student's $t$ test, which in this instance had a power of 0.62 , below the desired power of 0.80). Could the difference in time constant have arisen artifactually as the result of a systematic error in the curve-fitting procedure? Probably not: the algorithm is able to estimate to within $1 \%$ accuracy the time constant for the slowly decaying phase when asked to analyze families of theoretical curves in which a slow phase is mixed with varying amounts of a fast phase (not shown). The amplitude of the two components was similar (3.01 \pm 1.32 and $2.92 \pm 0.84 \mathrm{nA}$ at $90 \%$ of peak; $p=0.88$ by Mann-Whitney rank sum test). Thus, monoexponential ciliary neurons appear to be qualitatively different from neurons the EPSCs of which decay with two exponentials by two criteria: (1) differences in the fraction of the EPSC that is rapidly decaying and (2) differences in the time constant of decay for the slow phase. The difference in the time constants for these two populations implies that the burst duration for the underlying channels is different.

Ciliary neurons having little or no rapidly decaying EPSC component (i.e., "monoexponentials") accounted for $36 \%$ of neurons in the sample we encountered; however, this may not reflect the actual fraction of these neurons within the ganglion, because we recorded only from neurons at selected parts of the periphery of the ganglion. Our results are consistent with there being comparable numbers of the two types of neurons in the ganglion.

\section{Pharmacology of ciliary EPSCs}

We isolated each component of ciliary EPSCs pharmacologically with the use of the neurotoxins $\alpha$-BuTx and $\alpha$-CTx-MII. Within the ciliary ganglion, $95 \%$ of AChRs recognized by $\alpha$-BuTx contain $\alpha 7$ subunits (Pugh et al., 1995), whereas $\alpha$-CTx-MII is specific, among heterologously expressed mammalian AChRs, for $\alpha 3 \beta 2$ AChRs (Cartier et al., 1996). As illustrated in Figure 5A, 50 nM $\alpha$-BuTx reduced the peak amplitude of the EPSC and had less effect on the slowly decaying phase of the current (Fig. $5 A$, semilog trace). In all three instances when $\alpha$-BuTx was added to the bath while we recorded from a "biexponential" ciliary neuron, the EPSC was reduced to a single component of decay with a time course indistinguishable from that of the slow component present before addition of the toxin $(\tau=13.7 \pm 4.1 \mathrm{msec}$ before and $11.8 \pm 5.3 \mathrm{msec}$ after toxin; $p=0.65$ by paired Student's $t$ test). The amplitude of the slowly decaying component was reduced by $\sim 50 \%$ from that present before the addition of toxin (amplitude at $90 \%$ of peak $=2.62 \pm 0.88 \mathrm{nA}$ before and $1.30 \pm 0.55 \mathrm{nA}$ after; $p=0.005$ by paired $t$ test). In control experiments in which we maintained whole-cell recordings for $45 \mathrm{~min}$, the longest duration of a toxin experiment, we saw only a modest loss in amplitude of the EPSC or of either of its components $(3-10 \% ; n=4)$.

In four experiments in which we recorded from neurons in 200 nM rather than $50 \mathrm{~nm} \alpha$-BuTx, we found no statistically significant difference between the amplitude or time course of EPSCs recorded at these two concentrations ( $p=0.34$; Student's $t$ test).

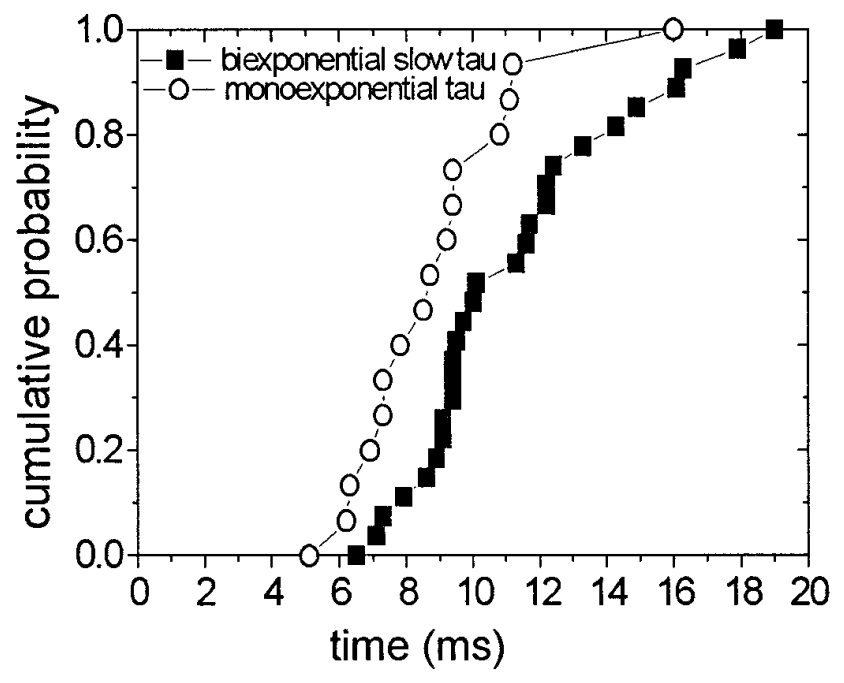

Figure 4. The time constant of decay for the slow phase of biexponential ciliary neurons differs from that of monoexponential ciliary neurons. Shown is a cumulative probability plot of the slow component of decay of biexponential ciliary EPSCs and the single component of decay of monoexponential ciliary EPSCs. The two populations of $\tau$ are significantly different ( $p=0.016$ by Student's $t$ test). This indicates that the biexponential and monoexponential neurons constitute two distinct classes of neurons, on the basis of the time constant of the slow phase of decay. 

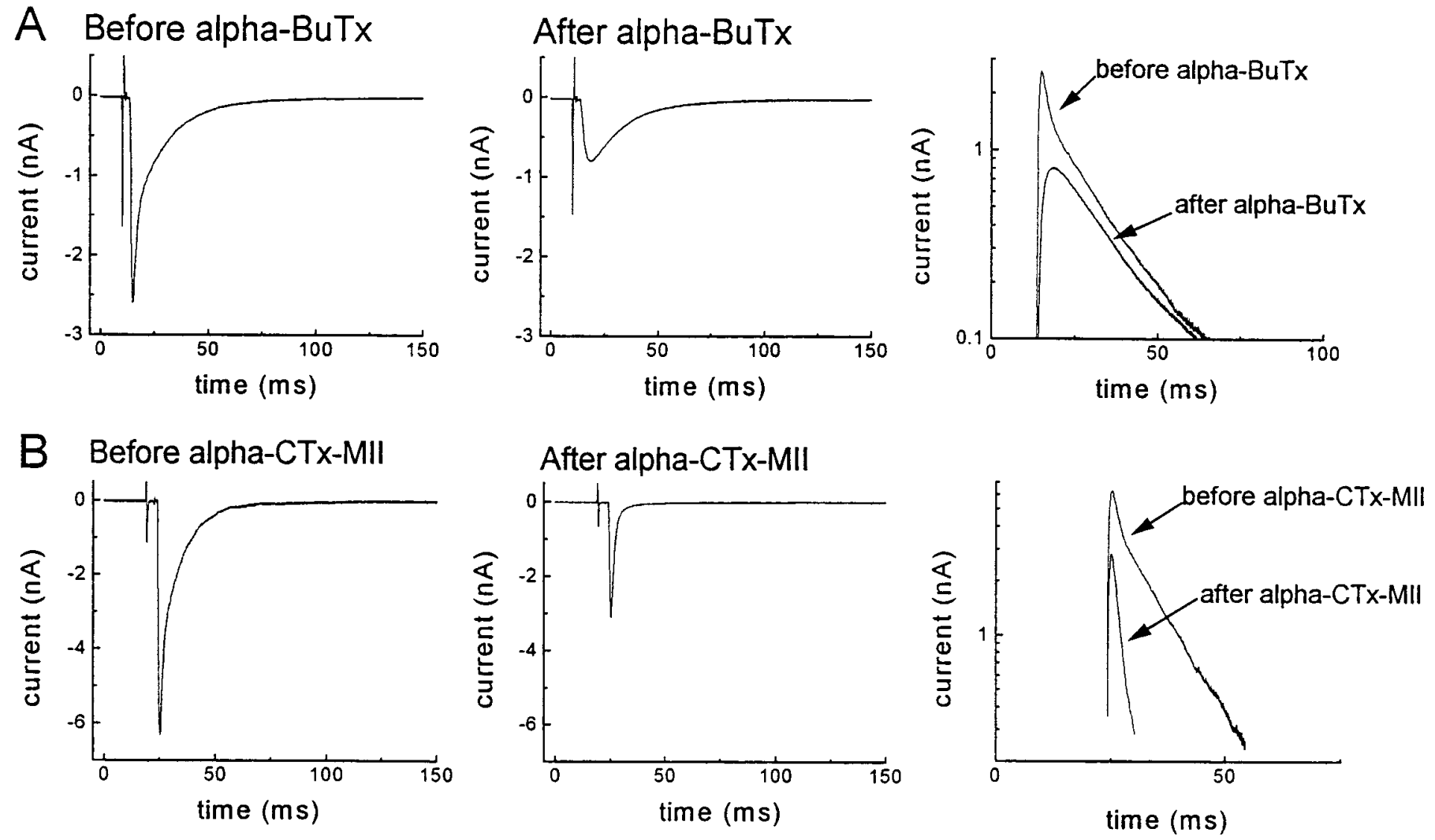

Figure 5. Effect of $50 \mathrm{~nm} \alpha$-BuTx $(A)$ and $50 \mathrm{~nm} \alpha$-CTx-MII $(B)$ on ciliary neuron biexponential EPSCs. The left trace in both $A$ and $B$ shows the EPSC from a ciliary neuron recorded before toxin addition. The middle trace shows the EPSC of the same cell after stabilization of the toxin effect. The right trace shows the semilog plots of the before- and after-toxin EPSCs. The rapidly decaying phase of current is eliminated by $\alpha$-BuTx, whereas the slowly decaying phase is eliminated by $\alpha$-CTx-MII.

Therefore, $50 \mathrm{~nm} \alpha$-BuTx has a maximal effect on both the fast and slow time course of the synaptic current.

The effects of $\alpha$-BuTx on ciliary neuron EPSCs were not readily reversible. In two experiments we were able to hold neurons for at least $30 \mathrm{~min}$ after toxin washout, and in each instance there was no measurable return of the rapidly decaying response nor was there an increase in the size of the slowly decaying response. $\alpha$-BuTx begins to have an effect within $5 \mathrm{~min}$ of its addition to the bath, and so the failure to see a recovery is presumably attributable to the fact that the toxin remains bound to its receptor.
$\alpha$-CTx-MII had an effect on biexponentially decaying ciliary neuron EPSCs that was complementary to that of $\alpha$-BuTx. Figure $5 B$ shows an example of the effects of $50 \mathrm{~nm} \alpha$-CTx-MII on a biexponentially decaying EPSC of a ciliary neuron. The toxin altered the trace to a monoexponentially decaying one, with a time constant of decay similar to that of the rapidly decaying component present beforehand; similar results were found in each of four other experiments. A comparison of the properties of the rapidly decaying phase before and after $\alpha$-CTx-MII suggests that its amplitude is unchanged $(90 \%$ of peak $=1.88 \pm 1.01$ and $2.15 \pm 1.00 \mathrm{nA}$, respectively; $p=0.18$ by paired $t$ test) but that its
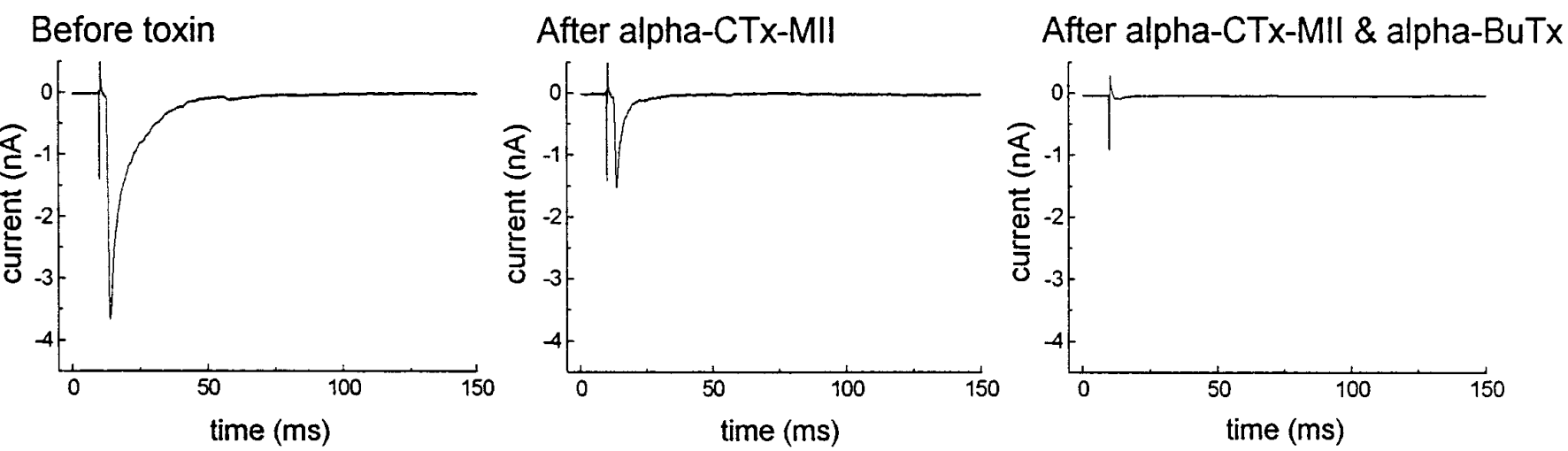

Figure 6. $\alpha$-CTx-MII and $\alpha$-BuTx together block the ciliary EPSC. The left panel shows a biexponential ciliary EPSC, the middle panel shows the EPSC of the same cell after addition of $50 \mathrm{~nm} \alpha$-CTx-MII, and the right panel shows the EPSC of the same cell after further addition of $50 \mathrm{~nm} \alpha$-BuTx. 

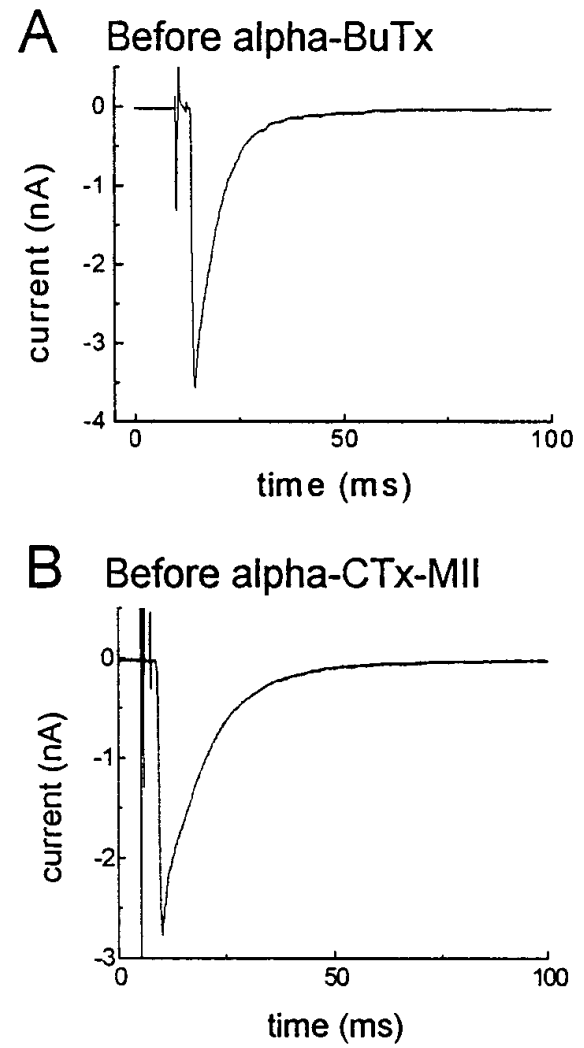
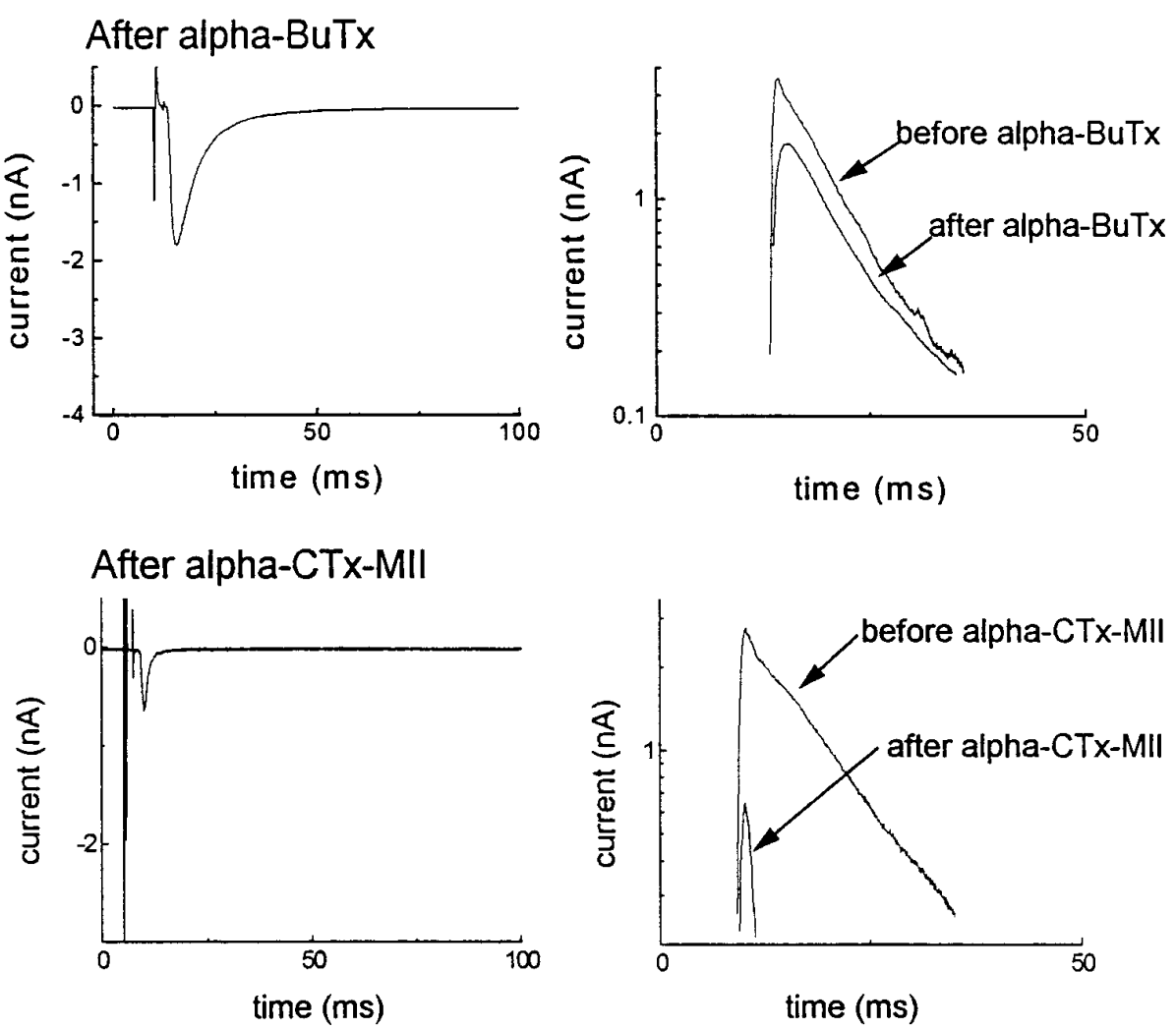

Figure 7. Effect of $50 \mathrm{~nm} \alpha$-BuTx $(A)$ and $50 \mathrm{~nm} \alpha$-CTx-MII $(B)$ on ciliary neuron monoexponential EPSCs. See legend to Figure 5 for complete description of traces. $\alpha$-BuTx reduces the peak of the EPSC but does not change its time course of decay $(A)$ ). $\alpha$-CTx-MII reduces the EPSC size substantially, eliminates the slowly decaying phase of current, and reveals a small, rapidly decaying phase of current $(B)$.

time constant is increased (from $1.16 \pm 0.35$ to $1.88 \pm 0.34 \mathrm{msec}$; $p=0.019$ by paired $t$ test). We believe, however, that this increase is only apparent and is the result of inaccuracies in the curvefitting procedure. Thus, when we construct artificial biexponentially decaying curves with $90 \%$ or more fast current $(\tau=1.2$ msec) and $10 \%$ or less slow current $(\tau=12.0 \mathrm{msec})$, the Clampfit curve-fitting algorithm, which examines the curve from $90 \%$ of peak to $10 \%$ of baseline, sometimes overestimates the time constant for the rapidly decaying component by up to $75 \%$ (yielding, for example, $1.8 \mathrm{msec}$ for a component that actually decays at 1.2 $\mathrm{msec})$. This can be understood by assuming that the program is unable to separate completely the two phases of decay and has "contaminated" the rapid phase with the slower phase. This was a problem only with curves with large amounts of rapidly decaying current and small amounts of slowly decaying current, and not vice versa.

The use of higher concentrations of $\alpha$-CTX-MII (200 nM) did not reduce the amplitude of the rapidly decaying component (data not shown). There was also no difference in the time course of EPSCs recorded in $50 \mathrm{~nm}$ versus $200 \mathrm{nM} \alpha$-CTx-M II $(p=0.7$ by Student's $t$ test). This implies that $\alpha$-CTx-MII, like $\alpha$-BuTx, has a maximal effect by $50 \mathrm{~nm}$.

Application of $50 \mathrm{~nm} \alpha$-CTx-MII followed by $50 \mathrm{~nm} \alpha$-BuTx blocked the ciliary neuron EPSC nearly completely (Fig. 6) (similar results were seen in two other experiments). This demonstrates that nicotinic AChRs sensitive to either $\alpha$-BuTx or $\alpha$-CTX-MII account for nearly all the synaptic current elicited from some ciliary neurons by nerve-released transmitter. In one ganglion we detected very small $(0.06 \mathrm{nA})$ currents in two of five neurons examined in the presence of both $200 \mathrm{~nm} \alpha$-BuTx and $200 \mathrm{~nm} \alpha$-CTX-M II (data not shown). This represents $1.4 \%$ of the peak current of the average ciliary EPSC. It is possible that some neurons contain a small-amplitude current insensitive to both toxins, but we cannot rule out trivial explanations, such as incomplete access of the toxins to all synaptic sites.

The effect of $\alpha$-BuTx and $\alpha$-CTx-MII on biexponentially decaying ciliary neuron EPSCs suggests that $\alpha$-BuTx blocks the rapidly decaying component and a fraction of the slowly decaying component of current, whereas $\alpha$-CTX-MII blocks the slowly decaying component of the current. In a few experiments we tested the effects of these toxins on monoexponentially decaying ciliary EPSCs and found that this current behaved pharmacologically like the slowly decaying component of biexponential EPSCs. Figure $7 A$ shows an example: $\alpha$-BuTx reduced the peak by $\sim 50 \%$ but did not affect the time constant of decay. In three experiments we found a significant reduction in the amplitude of the response $(2.43 \pm 1.03$ vs $1.27 \pm 0.71 \mathrm{nA} ; p=0.044$ by paired $t$ test) without a significant effect on the time constant of decay $(6.73 \pm 0.84$ vs $7.93 \pm 2.67 \mathrm{msec} ; p=0.4$ by paired $t$ test $)$. This argues that the slowly decaying components of the EPSC in "biexponential" and "monoexponential" ciliary neurons are pharmacologically similar, despite that fact that the time constants of their decay are different.

$\alpha$-CTx-MII had an effect on monoexponentially decaying ciliary EPSCs quite different from that of $\alpha$-BuTx. Figure $7 B$ shows an example in which $50 \mathrm{~nm} \alpha$-CTX-MII reduced the amplitude of the EPSC drastically; the surviving current had a decay considerably more rapid than that recorded beforehand. In six experi- 
Figure 8. Choroid neuron EPSCs are best fit with a single exponential. The left trace shows a choroid EPSC. The right trace shows the same EPSC replotted in semi$\log$ coordinates. All choroid EPSCs examined $(n=15)$ were best fit with a single exponential.
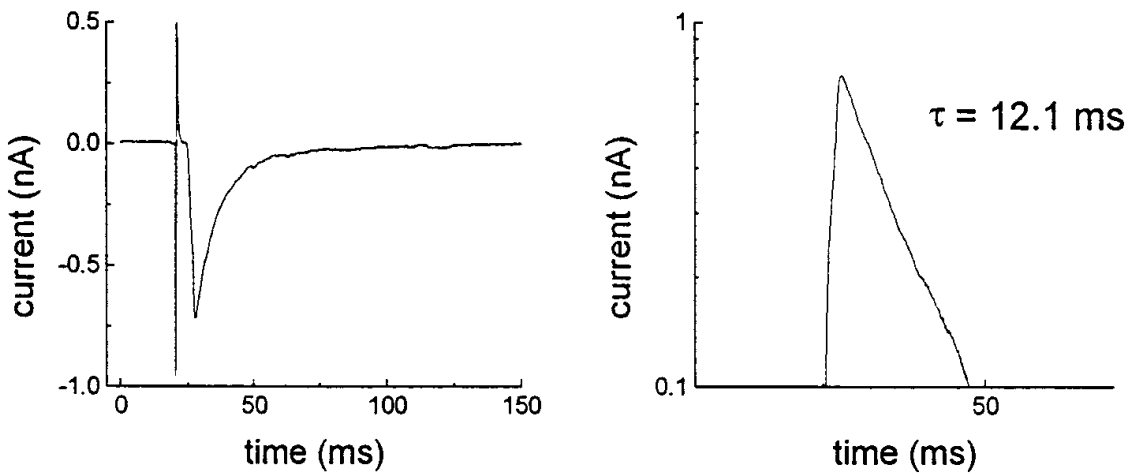

ments we found a pronounced effect on the amplitude of the monoexponentially decaying ciliary EPSCs (from $3.30 \pm 1.60$ to $0.62 \pm 0.19 \mathrm{nA} ; p=0.03$ by paired $t$ test) and a significant change in the time constant of decay (from $9.4 \pm 1.6$ to $1.5 \pm 0.5 \mathrm{msec}$; $p=0.0002$ by paired $t$ test). These results are consistent with the suggestion that ciliary EPSCs that appear to decay monoexponentially do indeed have a minor component of rapidly decaying current that is too small to detect by curve-fitting procedures but that can be unveiled with $\alpha$-CTx-MII. $\alpha$-BuTx may reduce the amplitude of these currents by eliminating the rapidly decaying component as well as some of the slowly decaying component.

\section{Choroid neuron EPSC kinetics and pharmacology}

Choroid neurons are distinct from ciliary neurons by having multiple inputs-as many as six. Because some of these inputs are small and produced EPSCs that fluctuated from trial to trial, we analyzed the kinetics and pharmacology of choroid neuron EPSCs by eliciting release from all preganglionic inputs simultaneously via maximal stimulation of the preganglionic nerve.

The decaying phase of choroid EPSCs was best described by a single exponential function in all instances $(n=15)$ (Fig. 8). The time constant describing the decay of choroid neuron EPSCs, $11.8 \pm 2.0 \mathrm{msec}$, was similar to that for the slow phase of EPSC decay for biexponential ciliary neurons ( $p=0.81$ by Student's $t$ test) but was significantly different from the corresponding value for monoexponentially decaying ciliary neuron EPSCs $(p=0.005$ by Student's $t$ test).

The pharmacological sensitivity of choroid neurons to $\alpha$-BuTx and $\alpha$-CTX-MII was similar to that of monoexponential ciliary EPSCs. Figure $9 A$ shows an example of the effects of $50 \mathrm{~nm}$ $\alpha$-BuTx on a choroid neuron EPSC. The peak response is reduced somewhat, with little effect on the decay phase of the current. In three experiments, $50 \mathrm{nM} \alpha$-BuTx reduced the amplitude of the EPSC (from $0.92 \pm 0.38$ to $0.34 \pm 0.16 \mathrm{nA} ; p=0.047$ by paired $t$ test) but had no significant effect on the time constant of EPSC decay $(12.8 \pm 3.5$ to $14.4 \pm 2.3 \mathrm{nA} ; p=0.12$ by paired $t$ test). By contrast, $\alpha-\mathrm{CTx}-\mathrm{MII}$ had a profound effect on choroid neuron EPSCs. Figure $9 B$ shows an example in which $50 \mathrm{~nm}$ $\alpha$-CTX-MII reduced the peak amplitude by well over $50 \%$; in four experiments $50 \mathrm{~nm} \alpha$-CTx-MII reduced the peak response by $84 \%(0.98 \pm 0.56$ to $0.12 \pm 0.09 \mathrm{nA} ; p=0.04$ by $t$ test $)$. The small component of $\alpha$-CTX-MII-resistant current decayed rapidly but was too small to permit us to measure its time constant accurately. The effects of $\alpha$-BuTx and $\alpha$-CTx-MII on choroid neuron EPSCs can be understood by assuming that like monoexponential ciliary EPSCs, choroid EPSCs contain a major component of slowly decaying current completely sensitive to $\alpha$-CTx-M II and partially sensitive to $\alpha$-BuTx and a minor component of rapidly decaying current sensitive to $\alpha$-BuTx.

\section{DISCUSSION}

We have analyzed the kinetics and pharmacology of EPSCs from ciliary ganglion neurons. Most of the ciliary neurons that we sampled had EPSCs that decayed biexponentially, with time constants of $\sim 1$ and $10 \mathrm{msec}$. The rapidly decaying component of the EPSC was completely blocked by $\alpha$-BuTx, whereas the slowly decaying component was partially blocked by $\alpha$-BuTx and completely blocked by $\alpha$-CTX-MII. The remainder of the ciliary neurons, and all sampled choroid neurons, had EPSCs that appeared to be monoexponential, having a time constant of $\sim 10$ msec; however, pharmacological evidence suggests that these neurons also had rapidly and slowly decaying components, with sensitivity to $\alpha$-BuTx and $\alpha$-CTx-MII similar to that of their biexponential counterparts. These findings complement the recent results of Zhang et al. (1996), who reported on the dual nature of EPSC decay of an unselected population of ciliary ganglion neurons and on the sensitivity of the rapidly decaying component of EPSC to $\alpha$-BuTx.

The two components of EPSC decay probably represent the behavior of different populations of AChR channels. If transmitter is present briefly in the synaptic cleft, such that no channels open for the first time during the falling phase of the EPSC, then the principal determinant of EPSC falling phase should be the channel burst duration. This implies that nerve-released ACh has access to at least two populations of receptor-channel complexes, and this interpretation is borne out by the pharmacological data.

Four populations of ACh channels have been detected on neurons cultured from embryonic day 14 ciliary ganglion, with conductances of 25, 40, 60, and 80 pS (Margiotta and Gurantz, 1989; J. Margiotta, personal communication). The open lifetime histograms for the 25 and $40 \mathrm{pS}$ channels were dominated by events having mean open times of $\sim 1 \mathrm{msec}$, whereas the 60 and $80 \mathrm{pS}$ events were briefer (0.1-0.3 msec). The 60 and $80 \mathrm{pS}$ events are abolished by $\alpha$-BuTx (J. Margiotta, personal communication), suggesting that they may underlie the rapidly decaying component of the EPSC, whereas the 25 and $40 \mathrm{pS}$ events may underlie the slowly decaying component of the EPSC. The difference between the mean open times and the EPSC decay time constants may reflect differences in the lifetimes of individual channel openings versus bursts of openings contributing to the falling phase of the EPSC.

The fast component of current decay is likely caused by $\alpha 7$ AChR, because of both its rapid time course and its sensitivity to $\alpha$-BuTx (Couturier et al., 1990; Anand et al., 1993; Zhang et al., 

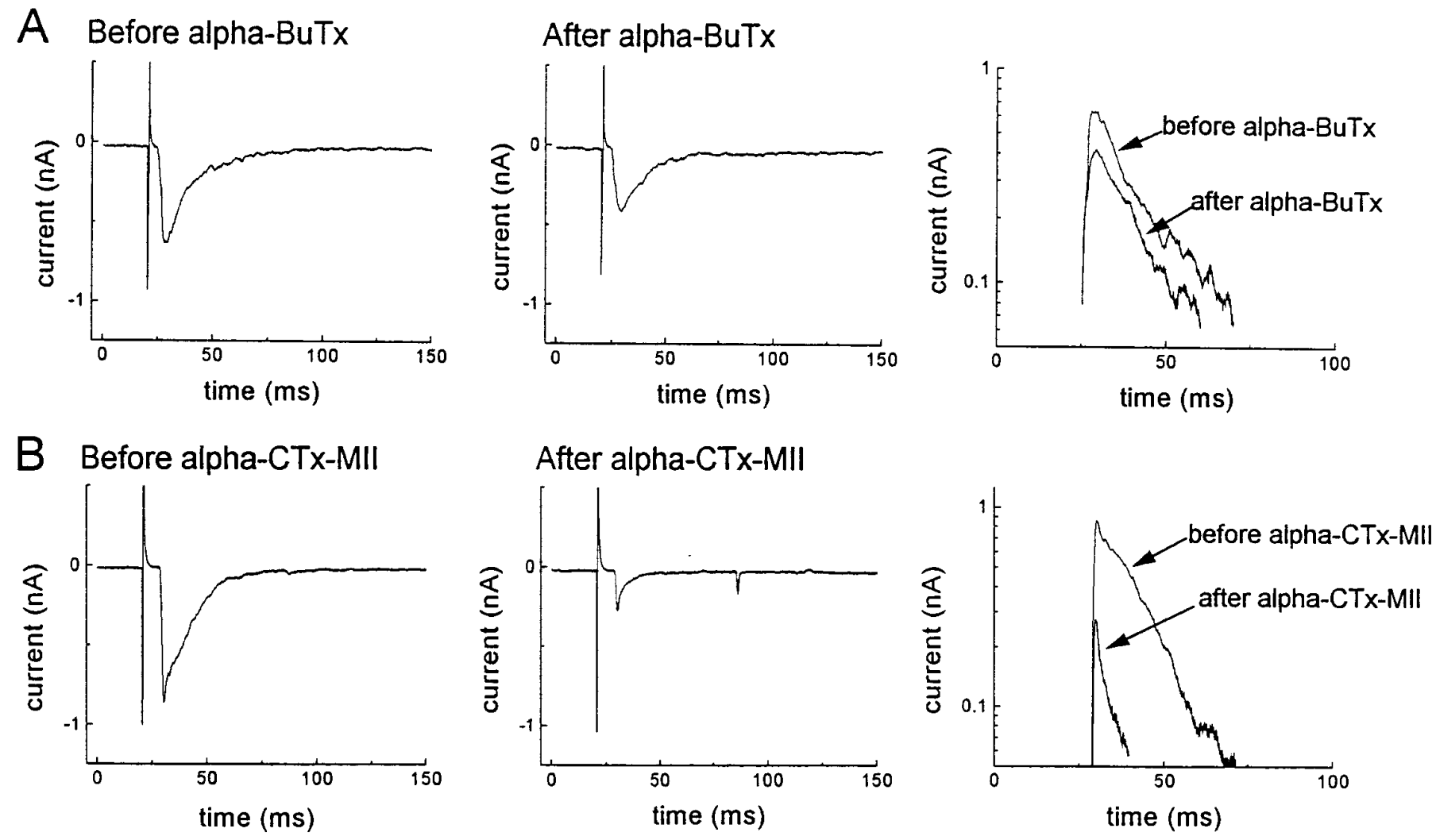

Figure 9. Effect of $50 \mathrm{~nm} \alpha$-BuTx $(A)$ and $50 \mathrm{~nm} \alpha$-CTx-MII $(B)$ on choroid neuron EPSCs. See legend to Figure 5 for complete description of traces. $\alpha$-BuTx reduces the peak of the EPSC but does not change the rate of decay $(A)$. $\alpha$-CTx-MII substantially reduces the EPSC size, eliminates the slowly decaying phase of current, and reveals a small, rapidly decaying phase of current $(B)$.

1994; Pugh et al., 1995). $\alpha 7$-containing AChRs are abundant in the ciliary ganglion (Conroy and Berg, 1995), and all ganglion neurons express $\alpha$-BuTx receptors (Jacob and Berg, 1983; Wilson Horch and Sargent, 1995). If the $20 \mathrm{fmol}$ of $\alpha$-BuTx AChRs in the ganglion (Conroy and Berg, 1995) were distributed evenly and exclusively among its 3000 neurons, then each neuron would have $\sim 4 \times 10^{6}$ receptors. If we take $70 \mathrm{pS}$ as an open channel conductance for these receptors (see above), then the single channel current would be $\sim 4 \mathrm{pA}$ with a driving force of $-60 \mathrm{mV}$. Only a few thousand such receptors, if activated synchronously, would be needed to produce the $\alpha$-BuTx-sensitive component observed.

$\alpha$-BuTx at 50 nм blocked most of the rapidly decaying EPSC and about half of the slowly decaying EPSC from biexponential ciliary neurons. Incomplete block of the slowly decaying current is not likely to have resulted from a partial occupancy of a lowaffinity AChR, because the block was not enhanced at $200 \mathrm{~nm}$ $\alpha$-BuTx. These data are consistent with the existence of two populations of $\alpha$-BuTx-sensitive AChRs, one of which is also sensitive to $\alpha$-CTX-MII. No known AChR subunit combination is sensitive to both $\alpha$-BuTx and $\alpha$-CTx-MII, including $\alpha 7$ homooligomers and $\alpha x \beta y$ hetero-oligomers in which $x=2,3$, or 4 , and $y=2$ or 4 (Johnson et al., 1995; Cartier et al., 1996). Perhaps $\alpha 7$-containing AChRs in the ganglion include both homooligomers, which presumably underlie the rapidly decaying EPSC component, and hetero-oligomers (Listerud et al., 1991); however, immunochemical studies (Vernallis et al., 1993; Conroy and Berg, 1995) have not found a detectable association between $\alpha 7$ subunits and other identified AChR subunits in the ganglion $(\alpha 3$, $\alpha 5, \beta 2$, or $\beta 4)$. Another possibility is that the AChRs that underlie the $\alpha$-BuTx-sensitive, slowly decaying EPSC are those recently identified by Pugh et al. (1995) that are recognized by $\alpha$-BuTx but have neither $\alpha 7$ nor any of the other AChR subunit gene products identified in the ganglion.

$\alpha$-CTx-MII is selective for $\alpha 3 \beta 2$ AChRs among mammalian types expressed in oocytes (Cartier et al., 1996) and may be blocking an AChR containing these subunits in the ciliary ganglion, given the high degree of homology between rat and chicken sequences (70-90\% at the amino acid level). The $\alpha 3$ and $\beta 2$ subunits are both present in the ciliary ganglion (Vernallis et al., 1993; Conroy and Berg, 1995), and immunoreactivity corresponding to both subunits is expressed in all neurons within the ganglion (H. L. Wilson Horch and P. B. Sargent, unpublished observations). Vernallis et al. (1993) and Conroy and Berg (1995) have found that all AChRs in extracts of the ganglion that contain immunoreactivity corresponding to the $\alpha 3$ and the $\beta 2$ subunits also contain the $\alpha 5$ and $\beta 4$ subunits. This suggests that the target for $\alpha$-CTX-MII may be an AChR oligomer with four different subunits.

Our pharmacological results on biexponential ciliary neurons are generally similar to those of Zhang et al. (1996). One difference is that we find that $50 \mathrm{~nm} \alpha$-BuTx has a more modest effect on peak EPSCs: the average reduction in the peak of the biexponential EPSC was $71 \%$ in our experiments and $92 \%$ in theirs. A second difference, which might be explained by differences in sampling, is that we found both neurons with biexponential EPSC decays and those with monoexponential decays, whereas Zhang et al. (1996) reported finding only neurons with biexponential 
decays. Finally, our time constants for the two phases of EPSC decay for the biexponential ciliary neurons were briefer than theirs (1.0 and $11.3 \mathrm{msec}$ vs 2.3 and $23.9 \mathrm{msec}$ ). Other than possible sampling differences, we can identify no obvious experimental differences between the protocol used by the two labs, or in the species or age of animals examined, that can explain these differences.

The two populations of ciliary neurons identified on the basis of their EPSC kinetics seem to differ both in the relative amount of "slow" and "fast" AChRs to which transmitter has access and possibly in the properties of the "slow" AChR channels, given that their burst durations are different. Subpopulations of ciliary neurons can be identified by differences in their projections (Pilar et al., 1980). Conceivably, neurons that project to different peripheral sites have distinct modes of transmission, perhaps because of differences in retrograde signals.

How many distinct AChR classes underlie the currents recorded from embryonic ciliary and choroid neurons? If each pharmacologically and kinetically distinct population of channel openings were to represent a unique $\mathrm{AChR}$, then there might be as many as five AChR populations differing in subunit composition and post-translational modification: three in ciliary neurons [(1) rapidly decaying, $\alpha$-BuTx sensitive, $\alpha$-CTx-MII resistant; (2) slowly decaying, $\alpha$-BuTx sensitive, $\alpha$-CTx-MII sensitive; and (3) slowly decaying, $\alpha$-BuTx resistant, and $\alpha$-CTx-MII sensitive] and two additional populations in choroid neurons (both $\alpha$-CTx-MII sensitive but differing in their resistance to $\alpha$-BuTx). The argument that the two components of current in choroid neurons represent AChRs distinct from their ciliary counterparts rests on their slower decay rates. Although the difference in decay rate is statistically significant, it is moderate $(25 \%)$ and may not "bear up" under further scrutiny.

The realization that $\alpha$-BuTx-sensitive AChRs underlie a significant component of synaptic current in many ciliary neurons comes as a surprise. For one, Chiappinelli and Dryer (1984) found that $\alpha$-BuTx did not block postganglionic compound action potentials. This is apparently because the synaptic currents recorded in the presence of $\alpha$-BuTx are still sufficient to reach threshold (Zhang et al., 1996). The role of $\alpha$-BuTx-AChRs in rapid transmission also is unexpected in light of the established location of these AChRs, which are principally perisynaptic (Jacob and Berg, 1983; Loring et al., 1985; Wilson Horch and Sargent, 1995). Is it possible that nerve-released transmitter diffuses to these perisynaptic sites and activates AChRs there? This scenario is feasible, given that the diffusion equation predicts that nerve-released transmitter can reach regions within $2 \mu \mathrm{m}$ of the release site in 1-2 msec. The rapid rise and fall of the synaptic current that is sensitive to $\alpha$-BuTx suggests that the AChRs underlying this current are activated fairly synchronously. This might be assured if these receptors, although extrasynaptic, are a consistent distance from release sites. Another possibility is that there are $\alpha$-BuTx-AChRs postsynaptically in numbers too small to be readily detected. Perhaps only a few thousand $\alpha$-BuTxAChRs need to be activated to produce the synaptic currents noted by us and by Zhang et al. (1996), and yet the presence of 20 fmol of $\alpha$-BuTx-AChRs per ganglion may translate into a million AChRs per neuron. The small numbers of putative synaptic $\alpha$-BuTx-AChRs might be nearly undetectable if they are distributed among the many active zones present on a single ciliary neuron. Zhang et al. (1996) reported that the addition of an acetylcholinesterase inhibitor did not enhance or prolong the $\alpha$-BuTx-sensitive synaptic current (although it did enhance the
$\alpha$-BuTx-insensitive currents). This suggests either that there is no acetylcholinesterase present within the synaptic cleft, a notion that conflicts with histochemical data (Fumagalli et al., 1982), or that the $\alpha$-BuTx-AChRs are saturated by nerve-released transmitter. Because it is difficult to imagine that nerve-released ACh could saturate a large number of extrasynaptic AChRs, perhaps the $\alpha$-BuTx-sensitive current may be produced when transmitter activates and saturates small synaptic clusters of $\alpha$-BuTx-AChRs. Inhibition of acetylcholinesterase might not enhance synaptic currents if perisynaptic $\alpha$-BuTx-AChRs desensitize before opening or if they are nonfunctional (Margiotta et al., 1987).

Why should there be two separate classes of AChRs underlying rapid synaptic transmission? The explanation seems not to be a meaningful increase in safety factor, because either receptor class alone provides for transmission with high reliability (Zhang et al., 1996). One intriguing possibility is that the two AChR classes are activated by different, physiologically relevant trains of stimuli. An additional possibility is that the high calcium permeability of the $\alpha$-BuTx-AChRs (Vijayaraghavan et al., 1992; Vernino et al., 1994) will prove to be meaningful: perhaps activation of these AChRs turns on a calcium-dependent second messenger system that is important for the maintenance of synaptic efficacy.

\section{REFERENCES}

Albuquerque EX, Alkondon M, Pereira EF, Castro NG, Schrattenholz A, Barbosa CT, Bonfante-Cabarcas R, Aracava Y, Eisenberg HM, Maelicke A (1997) Properties of neuronal nicotinic acetylcholine receptors: pharmacological characterization and modulation of synaptic function. J Pharmacol Exp Ther 280:1117-1136.

Anand R, Peng X, Lindstrom J (1993) Homomeric and native alpha7 acetylcholine receptors exhibit remarkably similar but non-identical pharmacological properties, suggesting that the native receptor is a heteromeric protein complex. FEBS Lett 327:241-246.

Boyd RT, Jacob MH, Couturier S, Ballivet M, Berg DK (1988) Expression and regulation of neuronal acetylcholine receptor mRNA in chick ciliary ganglia. Neuron 1:495-502.

Cartier GE, Yoshikami DJ, Gray WR, Luo SQ, Olivera BM, McIntosh JM (1996) A new alpha-conotoxin which targets alpha-3-beta-2 nicotinic acetylcholine receptors. J Biol Chem 271:7522-7528.

Chiappinelli VA, Dryer SE (1984) Nicotinic transmission in sympathetic ganglia: blockade by the snake venom neurotoxin kappa-bungarotoxin. Neurosci Lett 50:239-244.

Conroy WG, Berg DK (1995) Neurons can maintain multiple classes of nicotinic acetylcholine receptors distinguished by different subunit compositions. J Biol Chem 270:4424-4431.

Corriveau RA, Berg DK (1993) Coexpression of multiple acetylcholine receptor genes in neurons: quantification of transcripts during development. J Neurosci 13:2662-2671.

Couturier S, Bertrand D, Matter J-M, Hernandez M-C, Bertrand S, Millar N, Valera S, Barkas T, Ballivet M (1990) A neuronal nicotinic acetylcholine receptor subunit (alpha7) is developmentally regulated and forms a homo-oligomeric channel blocked by alpha-BTX. Neuron $5: 847-856$.

Decker MW, Brioni JD, Bannnon AW, Americ SP (1995) Diversity of neuronal nicotinic acetylcholine receptors: lessons from behavior and implications for CNS therapeutics. Life Sci 56:545-570.

Dryer SE (1994) Functional development of the parasympathetic neurons of the avian ciliary ganglion: a classic model system for the study of neuronal differentiation and development. Prog Neurobiol 43:281-322.

Dryer SE, Chiappinelli VA (1987) Analysis of quantal content and quantal conductance in two populations of neurons in the avian ciliary ganglion. Neuroscience 20:905-909.

Fumagalli L, Del Fa A, Olivieri-Sangiacomo C (1982) Surface AChE in the chick ciliary ganglion neurons: ultrastructural localization and possible relations to $\alpha$-bungarotoxin receptors. Neurochem Int 4:15-21.

Halvorsen SW, Schmid HA, McEachern AE, Berg DK (1991) Regulation of acetylcholine receptors on chick ciliary ganglion neurons by components from the synaptic target tissue. J Neurosci 11:2177-2186. 
Jacob MH, Berg DK (1983) The ultrastructural localization of alphabungarotoxin binding sites in relation to synapses on chick ciliary ganglion neurons. J Neurosci 3:260-271.

Jacob MH, Berg DK, Lindstrom JM (1984) Shared antigenic determinants between Electrophorus acetylcholine receptor and a synaptic component on chicken ciliary ganglion neurons. Proc Natl Acad Sci USA 81:3223-3227.

Johnson DS, Martinez J, Elgoyhen AB, Heinemann SF, McIntosh JM (1995) $\alpha$-Conotoxin ImI exhibits subtype-specific nicotinic acetylcholine receptor blockade: preferential inhibition of homomeric $\alpha 7$ and $\alpha 9$ receptors. Mol Pharmacol 48:194-199.

Lindstrom J (1996) Neuronal nicotinic acetylcholine receptors. In: Ion channels (Narahashi T, ed), pp 377-450. New York: Plenum.

Listerud M, Brussard AB, Kevay P, Colman DR, Role LW (1991) Functional contribution of neuronal AChR subunits by antisense oligonucleotides. Science 254:1518-1521.

Loring RH, Zigmond RE (1987) Ultrastructural distribution of ${ }^{125}$ I-toxin $\mathrm{F}$ binding sites on chick ciliary neurons: synaptic localization of a toxin that blocks ganglionic nicotinic receptors. J Neurosci 7:2153-2162.

Loring RH, Dahm LM, Zigmond RE (1985) Localization of alphabungarotoxin binding sites in the ciliary ganglion of the embryonic chick: an autoradiographic study at the light and electron microscopic level. Neuroscience 14:645-660.

Mandelzys A, Dekininck P, Cooper E (1995) Agonist and toxin sensitivities of ACh-evoked currents on neurons expressing multiple nicotinic ACh receptor subunits. J Neurophysiol 74:1212-1221.

Margiotta JF, Gurantz D (1989) Changes in the number, function, and regulation of nicotinic acetylcholine receptors during neuronal development. Dev Biol 135:326-339.

Margiotta JF, Berg DK, Dionne VE (1987) The properties and regulation of functional acetylcholine receptors on chick ciliary ganglion neurons. J Neurosci 7:3612-3622.

Martin AR, Pilar G (1963) Transmission through the ciliary ganglion of the chick. J Physiol (Lond) 168:464-475.

McGehee DS, Role LW (1995) Physiological diversity of nicotinic ace- tylcholine receptors expressed by vertebrate neurons. Annu Rev Physiol 57:521-546.

Pilar G, Landmesser L, Burstein L (1980) Competition for survival among developing ciliary ganglion cells. J Neurophysiol 43:233-254.

Pugh PC, Corriveau RA, Conroy WG, Berg DK (1995) Novel subpopulation of neuronal acetylcholine receptors among those binding alphabungarotoxin. Mol Pharmacol 47:717-725.

Role LW, Berg DK (1996) Nicotinic receptors in the development and modulation of CNS synapses. Neuron 16:1077-1085.

Sargent PB (1993) The diversity of neuronal nicotinic acetylcholine receptors. Annu Rev Neurosci 16:403-443.

Smith MA, Margiotta JF, Berg DK (1983) Differential regulation of acetylcholine sensitivity and $\alpha$-bungarotoxin-binding sites on ciliary ganglion neurons in cell culture. J Neurosci 3:2395-2402.

Vernallis AB, Conroy WG, Berg DK (1993) Neurons assemble acetylcholine receptors with as many as three kinds of subunits while maintaining subunit segregation among receptor subtypes. Neuron 10:451-464.

Vernino S, Rogers M, Radcliffe KA, Dani JA (1994) Quantitative measurement of calcium flux through muscle and neuronal nicotinic acetylcholine receptors. J Neurosci 14:5514-5524.

Vijayaraghavan S, Pugh PC, Zhang Z-W, Rathouz MM, Berg DK (1992) Nicotinic receptors that bind alpha-bungarotoxin on neurons raise intracellular free $\mathrm{Ca}^{2+}$. Neuron 8:352-363.

Wilson Horch HL, Sargent PB (1995) Perisynaptic surface distribution of multiple classes of nicotinic acetylcholine receptors on neurons in the chicken ciliary ganglion. J Neurosci 15:7778-7795.

Yawo H, Momiyama A (1992) Re-evaluation of calcium currents in preand postsynaptic neurons of the chick ciliary ganglion. J Physiol (Lond) 460:153-172.

Zhang Z, Coggan J, Berg D (1996) Synaptic currents generated by neuronal acetylcholine receptors sensitive to alpha-bungarotoxin. Neuron 17:1231-1240.

Zhang Z-W, Vijayaraghavan S, Berg DK (1994) Neuronal acetylcholine receptors that bind $\alpha$-bungarotoxin with high affinity function as ligandgated ion channels. Neuron 12:167-177. 